\title{
Fast training right on the national examination question for junior high school
}

\author{
Lailin Hijriani $^{1}$, Justin Eduardo Simarmata ${ }^{1}$, Meiva Marthaulina Lestari Siahaan ${ }^{1}$, \\ Ferdinandus Mone ${ }^{1}$, Eduardus Beo Seso Delvion ${ }^{1}$,Yosepha Patricia Wua Laja ${ }^{1}$, Merlin \\ Helentina Napitupulu ${ }^{1}$, Ni Putu Yuni Astriani Dewi ${ }^{1}$ \\ ${ }^{1}$ Universitas Timor, Nusa Tenggara Timur, Indonesia \\ *Email: elinhijriani@unimor.ac.id
}

\begin{abstract}
Community service activity aimed to provide an understanding of mathematical concepts consists of tips and tricks to solve exam questions for junior high school students. Furthermore, the background of the implementation of this training is to get students used to solve non-routine problems found during national examination, particularly in mathematics subject. This community service was carried out from October to November 2019 with 15 participants. This activity consists of three stages starting with the field assessment, the implementation stage and the last is final stage. In the field assessment stage, the servant determines the trainees to work national examination questions quickly and accurately that is specifically for junior high school students and determine where training will be held. The second stage is the implementation stage for exposuring to rapid strategies in administering national examination, question and answer, and national examination simulation. The final stage is the evaluation stage that is an implementation evaluation of theactivities that have been arranged based on each task that has been given .Based on the training activity that have been carried out it can be concluded that the training activity adds the knowledge and skills of students in working mathematics national examination questions. In addition, this training motivates students to be more active in learning mathematics and to be more mature in preparing for the upcoming national examination.
\end{abstract}

Keyword: training, national examination questions, junior high school students.

\begin{abstract}
Abstrak
Kegiatan pengabdian masyarakat bertujuan untuk memberikan pemahaman konsep matematika yang terdiri dari tips dan trik untuk menyelesaikan soal ujian bagi siswa SMP. Selanjutnya, latar belakang pelaksanaan pelatihan ini adalah untuk membiasakan siswa untuk menyelesaikan masalah-masalah non-rutin yang ditemukan selama ujian nasional, khususnya dalam mata pelajaran matematika. Pengabdian masyarakat ini dilakukan dari Oktober hingga November 2019 dengan 15 peserta. Kegiatan ini terdiri dari tiga tahap dimulai dengan penilaian lapangan, tahap implementasi dan yang terakhir adalah tahap akhir. Pada tahap penilaian lapangan, pelayan menentukan peserta pelatihan untuk mengerjakan soal-soal ujian nasional dengan cepat dan akurat yang khusus untuk siswa sekolah menengah pertama dan menentukan di mana pelatihan akan diadakan. Tahap kedua adalah tahap implementasi untuk mengekspos strategi cepat dalam mengelola ujian nasional, tanya jawab, dan simulasi ujian nasional. Tahap akhir adalah tahap evaluasi yaitu evaluasi pelaksanaan kegiatan yang telah disusun berdasarkan setiap tugas yang telah diberikan. Berdasarkan kegiatan pelatihan yang telah dilakukan dapat disimpulkan bahwa kegiatan pelatihan menambah pengetahuan dan keterampilan siswa dalam mengerjakan soal ujian nasional matematika. Selain itu, pelatihan ini memotivasi siswa untuk lebih aktif dalam belajar matematika dan lebih matang dalam mempersiapkan ujian nasional yang akan datang.
\end{abstract}

Kata Kunci : Pelatihan, Pertanyaan Ujian Nasional, Siswa SMP.

\section{PENDAhUluaN}

Pendidikan menjadi tolok ukur kemajuan suatu negara. Semakin baik kualitas pendidikannya maka sumber daya yang dihasilkan pun semakin unggul. Salah satu alat ukur untuk melihat keberhasilan suatu penyelenggaraan pendidikan secara nasional ialah Ujian Nasional (UN). Permendikbud No. 66 Tahun 2013 menyatakan bahwa Ujian Nasional merupakan kegiatan pengukuran kompetensi tertentu yang dicapai peserta didik dalam rangka menilai pencapaian kriteria minimal tentang 
sistem pendidikan yang termuat dalam Standar Nasional Pendidikan yang dilaksanakan secara nasional.

Untuk tercapainya tujuan pembelajaran, guru dan siswa harus saling bersinergi dalam memegang perannya masing-masing. Selain kewajiban siswa menerima pembelajaran dan mempertanggung jawabkan apa yang ia sudah pelajari dalam bentuk assessment, guru juga diharapkan sensitive dalam melihat kebutuhan siswa. Misalnya, untuk siswa SMP kelas IX yang akan menghadapi UN. Mereka harus diperhadapkan dengan konsep yang kemudian dituangkan dalam bentuk soal yang bervariasi bukan hanya soal rutin.

Faktanya, kebanyakan guru di sekolah berkewajiban untuk menyelesaikan seluruh materi yang ada di silabus. Memang karena seperti itu aturannya. Namun karena hal itu, guru hanya focus menyelesaikan materi sehingga memberikan contoh soal atau soal rutin. Padahal soal yang akan dihadapi di UN bukan hanya soal rutin. Implikasinya ketika siswa menjalani try out, mereka mengalami kesulitan dalam menjawab soal simulasi UN tersebut.

Sederhananya, para siswa harus dibiasakan dengan soal tidak rutin sehingga kemampuan penalaran mereka dalam menghadapi variasi masalah dapat terus terasah. Hal ini selaras dengan data TIMSS (The Trend in International Mathematics and Science Study) yang menunjukkan kemampuan matematika siswa yang menitikberatkan pada kemampuan Knowing (pengetahuan) sebanyak 35\% siswa memberikan jawaban benar, pada Applying (penerapan) sebanyak $40 \%$, dan Reasoning (penalaran) sebanyak 25\%. Dari data ini diketahui bahwa kemampuan penalaran siswa yang paling rendah.

Untuk itu, diperlukan bantuan dari pihak ketiga, dalam hal ini bimbingan belajar, yang membantu guru dan juga siswa dalam menghadapi soal-soal UN. Metode yang diberikan juga harus tepat sasaran. Melihat dari kesenjangan ini yang diperlukan siswa ialah pengklasifikasian konsep dan materi juga trik dalam mengerjakan soal dengan mengaplikasikan konsep yang digunakan. Berkaitan dengan masalah di atas, pembentukan pelatihan mengerjakan soal UN Matematika dengan cepat dan tepat merupakan solusi yang diharapkan dapat membantu siswa terutama siswa SMP dalam menghadapi UN.

\section{METODE PELAKSANAAN}

Sasaran kegiatan ini adalah semua siswa kelas IX SMP LBKP U-Genius Kefamenanu, Nusa Tenggara Timur. Kegiatan dilaksanakan di Ruang Kelas yang diikuti 15 orang. Adapun yang menjadi instruktur dan narasumber dalam kegiatan ini adalah Dosen-dosen Program Studi Pendidikan Matematika, Program Studi Pendidikan Bahasa Inggris, dan Program Studi Pendidikan Biologi Universitas Timor, Kefamenanu.

Metode yang digunakan dalam kegiatan ini adalah ceramah interaktif yang dipilih untuk menyampaikan pelatihan cepat tepat dalam menghadapi Ujian Nasional yang dilaksanakan dalam tiga tahapan yaitu tahap penjajakan lapangan, tahap implementasi, dan tahap evaluasi. Tahap penjajakan lapangan dimulai dari menentukan peserta pelatihan yaitu siswa siswi SMP, persiapan berbagai administrasi yang diperlukan, melakukan koordinasi dengan Direktur LBKP U-Genius Kefamenanu, persiapan materi dann soal-soal pelatihan, persiapan narasumber yang kompeten dan relevan, serta persiapan jadwal kegiatan. Tahap implementasi berupa paparan strategi cepat tepat dalam menghadapi Ujian Nasional (ceramah), tanya jawab (interaktif), serta simulasi Ujian Nasional. Berikutnya tahap terakhir yaitu tahap evaluasi, pada tahap ini kegiatan yang dilakukan yaitu evaluasi terhadap implementasi kegiatan yang telah di susun baik tugas ketua tim pelaksana ataupun anggota tim pelaksana. Adapun tempat dilakukannya pelatihan cepat tepat mengerjakan soal UN untuk SMP ini yaitu di LBKP U-Genius Kefamenanu 


\section{HASIL DAN PEMBAHASAN}

Sesuai dengan rencana yang telah ditentukan sebelum kegiatan pelatihan dilaksanakan, kegiatan ini diawali dengan penyiapan berbagai administrasi yang diperlukan antara lain permohonan izin melaksanakan pengabdian masyarakat, koordinasi dengan Direktur LBKP U-Genius Kefamenanu untuk menentukan jadwal. Peserta kegiatan ini adalah seluruh siswa kelas IX SMP LBKP UGenius Kefamenanu. Kegiatan ini diawali dengan persiapan dan perkenalan/pembukaan. Hal ini dilakukan agar narasumber terlebih dahulu mengenal karakter para siswa/i serta tempat berlangsungnya kegiatan. Kemudian kegiatan inti/tahapan implementasi berlangsung selama kurang lebih 3,5 jam. Diawali dengan ceramah dari narasumber kemudian tanya jawab (interaktif) dan di akhiri dengan pelatihan atau simulasi UN khususnya bidang studi matematika.

Kegiatan pengabdian masyarakat yang dilaksanakan telah berlangsung dengan baik. Hal ini terlihat dari animo dan semangat peserta untuk mengikuti kegiatan ini, terbukti dengan kehadiran peserta untuk mengikuti kegiatan. Hal ini mengindikasikan bahwa para peserta menyambut positif kegiatan yang telah dilakukan. Direktur LBKP U-Genius beserta staff pengajar dan para siswa menyambut antusias terkait pelaksanaan kegiatan ini. Direktur bahkan berharap agar kegiatan ini dilakukan secara berkesinambungan.

\section{KESIMPULAN}

Masalah siswa dalam menghadapi UN adalah: 1) Berkaitan dengan diri sendiri yaitu perasaan belum percaya diri saat akan mengerjakan soal UN dan belum mengetahui trik cepat dalam mengerjakan soal UN; 2) Berkaitan dengan fasilitas pembelajaran yaitu kesulitan belajar karena tidak adanya buku pelajaran yang lengkap dan kurang jelas dengan soal-soal UN yang diberikan karena materinya tidak sesuai dengan yang disampaikan guru.

\section{UCAPAN TERIMAKASIH}

Ucapan terima kasih dihaturkan kepada Rektor Universitas Timor Kefamenanu beserta staff nya yang telah mengizinkan kami turut berpartisipasi dalam kegiatan pengabdian kepada masyarakat. Ucapan yang sama kami tujukan untuk Dekan FIP dan Ketua Program Studi Pendidikan Matematika Universitas Timor, Kefamenanu, Nusa Tenggara Timur.

Terima kasih juga kami sampaikan kepada Ketua UPT LPPM Universitas Timor Kefamenanu beserta staff nya yang selalu membantu kami dalam sisi administratif. Selanjutnya kami juga mengucapkan terima kasih kepada Direktur Lembaga Bimbingan dan Kursus Pelatihan (LBKP) U-Genius, Staff pengajar, dan para siswa/siswi SMP Kelas IX LBKP U-Genius, Kefamenanu, Nusa Tenggara Timur, karena atas bantuannya pengabdian kepada masyarakat ini dapat dilaksanakan dengan baik dan lancar. Serta kepada pihak lain yang tidak dapat disebutkan satu persatu.

\section{DAFTAR PUSTAKA}

Arief, Furchan. 2009. Mengatasi Kecemasan Menghadapi Ujian. Remaja Rosdakarya: Bandung.

Anas Sudijono. 2001. Statistik Pendidikan. Raja Grafindo Persada: Jakarta.

Arikunto, S. 2010. Dasar-Dasar Evaluasi Pendidikan (Edisi Revisi). Jakarta: Bumi Aksara.

Asri Budiningsih. 2004. Belajar dan Pembelajaran. Yogyakarta: Penerbit Rinika Cipta.

Casbarro J. 2005. Anxiety Disorder an Introduction to Clinical Management Research . New York. 
Lailin Hijriani et.al. Fast Training Right

Dwita, dkk. 2002. Kecemasan yang Dihadapi Siswa Saat Ujian Nasional. Internet: www.google.com

Depdiknas. 2008. KBBI Daring. Dipetik Februari 07, 2012, dari Pusat Bahasa

Mungin Eddy Wibowo. 2012. Kondisi Psikologi Siswa Dalam Menghadapi Ujian Nasional dan Cara Mengatasinya. Semarang: Abkin ICT Team. 